\title{
O PROBLEMA DA TRANSCENDÊNCIA DO OBJETO DA PERCEPÇÃO E DO OBJETO DA FÍSICA NAS INVESTIGAÇÕES LÓGICAS DE HUSSERL ${ }^{1}$
}

\section{Savio Passafaro Peres (PUC-SP) ${ }^{2}$}

elatoriomachado@yahoo.com.br

\begin{abstract}
Resumo: É bem sabido que na primeira edição de Investigações Lógicas (1900/1901), Husserl delimita o domínio de investigação da fenomenologia como imanência psicológica. Contudo, se examinarmos detidamente os critérios empregados para a delimitação da imanência psicológica, constatamos que eles implicam determinada concepção de transcendência do objeto intencional. Esta concepção de transcendência conduz a dificuldades epistemológicas concernentes à relação entre o objeto da física e o objeto da percepção. Afinal, seria correto afirmar que o objeto da física é transcendente no mesmo sentido com que se afirma que o objeto percebido é transcendente à vivência de perceber? Este artigo procura mostrar como a virada transcendental de 1906/1907, e a consequente distinção entre três conceitos de imanência e transcendência em Ideia de Fenomenologia contribuíram para Husserl solucionar tais problemas.
\end{abstract}

Palavras-chave: Edmund Husserl; fenomenologia; imanência; transcendência.

\section{INTRODUÇÃO}

Uma vez que o tema deste artigo diz respeito à relação entre imanência e transcendência, é preciso destacar as diferenças entre a edição de 1900/1901 de Investigações Lógicas e a edição revisada de 1913. Algumas das mais importantes modi-

\footnotetext{
${ }^{1}$ Recebido em: 12-06-2014/Aprovado: 05-08-2014/Publicado on-line: 08-09-2014.

${ }^{2}$ Savio Passafaro Peres é Professor e Pós-doutor no departamento de Filosofia da Pontífica Universidade Católica de São Paulo, São Paulo, SP, Brasil.
} 
ficações de 1913 foram efetuadas em vista de uma rearticulação entre imanência e transcendência, de modo a alargar o campo da fenomenologia (BOEHM 1968). Esse alargamento do campo da fenomenologia é consequência da compreensão alcançada por Husserl, por volta de 1906/1907, de que a fenomenologia não é psicologia descritiva, mas filosofia transcendental, tendo como domínio a consciência pura. Dadas tais circunstâncias, devemos nos limitar, inicialmente, à primeira edição de $\mathrm{LU}^{3}$, para em um segundo momento, debruçarmo-nos nas análises acerca do sentido de suas modificações na segunda edição concernentes ao problema da imanência ou transcendência do objeto da percepção. Apenas assim teremos os dados para abordar frontalmente a articulação realizada por Husserl no que concerne ao problema da relação entre o objeto da física e o objeto da percepção em Ideias para uma fenomenologia pura e para uma filosofia transcendental.

Por objeto da física, entendemos os entes a respeito dos quais a física moderna, a partir de Newton, busca investigar, como, por exemplo, átomos ou estruturas atômicas e químicas. Trata-se fundamentalmente de objetos descritos em termos lógico-matemáticos. As ciências naturais e especialmente a física não pretendem investigar a realidade interna, psicológica do sujeito, mas a realidade externa. Por objeto da percepção externa, entendemos tudo aquilo que aparece em nosso mundo circundante, como estrelas, cadeiras e cachorros. A pergunta que se segue é: qual a relação

\footnotetext{
${ }^{3}$ A partir daqui, usarei como base, salvo indicação contrária, a edição de 1901, a qual será indicada com a sigla LU. O conteúdo da primeira edição pode ser encontrado na edição portuguesa (HUSSERL 2007, 2012), a qual apresenta, no corpo do texto, tanto as edições de 1900/1901 quanto a edição revista de 1913. Também usamos como referência a edição alemã de 1901, a qual pode ser facilmente encontrada na internet, como segue o link nas referências bibliográficas.
} 
entre o objeto dado na percepção e o objeto físico? Uma forma muito popular de se responder essa questão é conhecida como teoria representacionalista da percepção. Segundo essa teoria, se eu vejo uma mesa, isso ocorre porque fótons estimularam minha retina, desencadeando impulsos nervosos que são processados no cérebro, de modo a emergir em mim uma representação consciente da mesa. Ou seja, a mesa exterior afeta o meu sistema sensorial, de modo a produzir em mim uma representação ou imagem mental da mesa. Assim, teríamos, de acordo com essa teoria, duas mesas: uma interna, que é conteúdo de consciência, resultante de processos cerebrais, e uma mesa física externa, que, ao ser iluminada, difrata a luz, emitindo fótons que estimulam o aparelho sensorial. Com isso, o representacionalismo postula a existência de duas entidades implicadas na percepção: um objeto extramental e uma representação intramental.

Husserl rejeita essa forma de representacionalismo já em LU. Para ele, ao ver uma mesa, não estamos conscientes de uma imagem mental da mesa ou de uma representação da mesa, mas sim da mesa ela própria, dada em pessoa. É verdade, afirma Husserl, que a impressão sensorial da mesa ou aparição da mesa é uma vivência e, portanto, conteúdo de consciência, mas o que percebemos não é a impressão ou a aparição, mas a própria mesa. A mesa percebida de que estamos conscientes é algo transcendente à vivência. Ou seja, é preciso distinguir cuidadosamente o objeto percebido da vivência de perceber. A vivência de perceber, bem como a aparição do objeto, é um autêntico conteúdo de consciência, ao passo que o objeto percebido aparecente não. Husserl defende que, na percepção, visamos diretamente o objeto transcendente, sem a mediação de uma representação ou imagem mental. Um de seus argumentos 
para isso é um argumento descritivo. A consciência perceptiva é um modo intencional descritivamente distinto da consciência de imagem (Bildbewusstsein). Ser imagem não é uma propriedade do objeto, como ser vermelho, mas algo que o objeto percebido adquire em função de uma nova forma de intencionalidade, que o interpreta como representante de outro objeto. Por mais que dois objetos sejam semelhantes, isso não faz de um uma imagem do outro, assim como a similitude não faz de um gêmeo a imagem de seu irmão. Para que um objeto seja uma imagem, é necessário que ele seja interpretado como representando outro. Em suma, toda consciência de imagem pressupõe a consciência de dois objetos, o objeto-imagem e o objeto-sujeito. Contudo, uma correta descrição da consciência perceptiva mostra que nela estamos conscientes apenas de um único objeto.

\section{A DELIMITAÇÃO DA IMANÊNCIA NA PRIMEIRA EDIÇÃO DE INVESTIGAÇÕES LÓGICAS}

A elucidação descritiva do sentido pelo qual o objeto percebido é transcendente possui várias implicações e pede esclarecimentos. E uma das melhores formas de alcançarmos esse esclarecimento é iniciarmos com uma análise do que Husserl entende por consciência e por conteúdos de consciência. Este tema ocupa boa parte da quinta LU. Nela, Husserl observa que o termo consciência carrega vários conceitos que devem ser distinguidos:

1. Consciência como interno dar-se conta das vivências psíquicas. Diz respeito ao fato de que toda consciência é também autoconsciência, ainda que não seja uma autoconsciência realizada de modo explícito, por meio de um 
ato reflexivo ou de um ato de percepção interna ${ }^{4}$. Zahavi (2002) aponta que esta forma de consciência diz respeito ao caráter intransitivo das vivências, isto é, ao fato de que toda vivência é uma unidade de consciência que se manifesta a si mesma, sem, por isso, devir objeto.

2. Consciência como designação global para todo e qualquer tipo de ato psíquico. Trata-se da consciência tomada como "consciência de algo", como vivência intencional e, portanto, concerne ao caráter transitivo das vivências (ZAHAVI 2002). Estudar a consciência neste sentido é estudar os atos de consciência.

3. Consciência como consistência fenomenológica do eu. Este conceito delimita a consciência como a unidade da totalidade do fluxo de vivências, como explicitado por Husserl "[...] a consistência conjunta do eu espiritual. (consciência $=$ eu fenomenológico, enquanto feixe ou entrelaçamento de vivências psíquicas)" (HUSSERL 1901/2012, 296). Como Husserl na primeira edição rejeita a noção de eu puro e trabalha com uma concepção nãoegológica de consciência (2012, 309-312; cf. 1901, 340344), o eu fenomenológico nada mais é do que o próprio fluxo de vivências. Segundo Husserl, este é o conceito de consciência mais difundido na psicologia moderna, a qual pode ser determinada pelas seguintes expressões correlatas: "ciência de indivíduos psíquicos enquanto consciência", "ciência de vivências da consciência", "ciência de conteúdos de consciência”. Husserl concorda com a posição difundida

\footnotetext{
${ }^{4} \mathrm{O}$ termo "percepção interna" possui em Husserl um sentido distinto do que em Brentano. Para Husserl, percepção interna é um ato reflexivo, que ocorre, portanto, ocasionalmente, quando uma vivência é tematizada e, portanto, torna-se alvo de uma vivência reflexiva. Em Brentano, trata-se de uma característica intrínseca a todo ato e diz respeito ao fato de que todo ato é consciente não apenas de seu conteúdo, mas também de si mesmo.
} 
por Wundt, de acordo com o qual os conteúdos de consciência são vivências. As vivências são marcadas pela temporalidade, devem ser entendidas como "ocorrências reais", como "fatos psíquicos", que "mudam de momento para momento", "se interligam e se interpenetram de muitos modos" de maneira a constituir "consciência do respectivo indivíduo psicofísico". (HUSSERL 1901/2012, 296). Para Husserl, tal conceito de vivência constitui a concepção de conteúdo de consciência em sentido autêntico ${ }^{5}$, que são também denominados, na primeira edição, de "conteúdos reells", "conteúdos fenomenológicos" ou "conteúdos psicológicos descritivos"?. (HUSSERL 2012, 341; 1901, 374). Na primeira edição é justamente esse terceiro conceito de consciência que delimita o campo da fenomenologia, que nada mais é do que a unidade dos conteúdos reells ou autênticos de consciência. Por conteúdo reell Husserl entende todo tipo de vivências, intencionais ou não, como percepções, representações de fantasia, representações de imagem, esperanças, temores, sensações, etc, que tem lugar em seres psicofísicos, além de qualquer parte da vivência.

\footnotetext{
${ }^{5}$ Também nas LU Husserl alerta que o discurso sobre conteúdo de consciência é ambíguo. Por isso, ele distingue conteúdos de consciência em sentido próprio (eigentlich) e impróprio (uneigentlich).

${ }^{6} \mathrm{O}$ adjetivo "reell" usualmente é traduzido para o português como real. Contudo, isso pode gerar graves confusões, pois o termo alemão "real" também é traduzido por "real". Na edição portuguesa de Investigações Lógicas (2012), os tradutores optaram por empregar o termo "real" para a tradução de ambos os termos, indicando em nota o termo alemão. Na tradução de A ideia de fenomenologia (2007), o tradutor emprega o termo "ingrediente" para traduzir o adjetivo alemão "reell". Como essa última tradução pressupõe uma interpretação do termo, preferi evitá-la. Optei, a fim de evitar recorrer constantemente às notas de rodapé, manter a expressão original reell. Como o uso da forma plural em alemão correspondente tornaria o texto demasiado esquisito, o plural foi formado pelo simples acréscimo da letra "s".

${ }^{7}$ Em 1901, o fluxo de vivências reais circunscreve o domínio da psicologia e, portanto, também da fenomenologia, já que esta é entendida como uma forma de psicologia descritiva (HUSSERL 2012, 16; 1901,18). Isso explica por que, na primeira edição, Husserl usa como sinônimo "conteúdos fenomenológicos" e "conteúdos psicológico-descritivos".
} 
Conteúdos de consciência em sentido próprio são vivências e nada além de vivências. Sobre estas, Husserl faz as seguintes considerações:

1. Apenas vivências são vivenciadas. Portanto um objeto exterior sensível, um estado de coisas ou uma entidade ideal, não podem propriamente ser vivenciados. Toda transcendência é uma não-vivência (HUSSERL 1901/2012, 300; 1901, 330).

2. As vivências constituem o fluxo de consciência.

3. O fluxo de consciência tem lugar em indivíduos psicofísicos (HUSSERL, 1901/2012, 296).

4. As partes de uma vivência compartilham da mesma natureza da vivência: são vividas, fazem parte do fluxo e são tão singulares quanto as vivências concretas. Ou seja, toda parte de uma vivência é um conteúdo reell da vivência. Dois conteúdos em sentido próprio (reell) nunca são os mesmos e são numericamente distintos.

\section{O PROBLEMA DA RELAÇÃO ENTRE TRANSCENDÊNCIA E IMANÊNCIA EM INVESTIGAÇÕES LÓGICAS}

Husserl afirma em LU que o objeto intencionado é transcendente ao ato. Contudo, é preciso observar que não há, nesta obra, um detalhamento esclarecedor da natureza desta transcendência, como bem afirma Boer $(1978,135)$ :

Husserl apela para a evidência do fato que na percepção nós percebemos coisas - coisas transcendentes. Sem mais discutir a natureza da transcendência, devo ao menos estabelecer que a coisa percebida manifesta-se como um objeto transcendente à consciência. Portanto, esta coisa não pode ser identificada com as sensações que estão presentes na consciência ela mesma.

Husserl, guiado por sua ideia de que a fenomenologia é 
uma ciência puramente descritiva e metafisicamente neutra, limita-se a afirmar que o objeto não se encontra descritivamente no ato, ou seja, em seu conteúdo psicológico-descritivo. Estar consciente de algo transcendente é estar consciente de algo que é descritivamente distinto de uma vivência. Ou seja, a estratégia de Husserl para defender a transcendência do objeto é mostrar que os traços descritivos do objeto são distintos dos traços descritivos tanto das vivências quanto de suas partes. Uma vez que a vivência é uma ocorrência real, ela não pode se repetir, mas o mesmo objeto pode ser intencionado em múltiplas vivências distintas e deve ser descrito como um mesmo objeto. Cada percepção do objeto é um evento psíquico que dura enquanto durar a percepção, ao passo que o objeto deve ser descrito como algo que permanece numericamente o mesmo. Se o objeto fosse uma vivência, ele não poderia se repetir, pois uma vivência é descritivamente e numericamente distinta da outra. $\mathrm{O}$ objeto intencional também não pode ser parte da vivência, pois toda parte de uma vivência, abstrata ou concreta, compartilha a mesma natureza irrepetível da vivência (HUSSERL 2012, 341/358). No caso da percepção exterior, é possível que duas vivências de percepção distintas sejam direcionadas ao mesmo objeto. Vejo essa mesa, tenho, portanto, uma vivência dirigida para ela. Fecho os olhos, abro-os novamente e agora tenho uma nova vivência de percepção da mesa. As vivências são distintas, tanto no todo como em cada uma de suas partes, contudo, o objeto é visado como o mesmo. O objeto deve ser descrito como sendo o "mesmo", como "permanente" ao passo que as vivências e suas partes devem ser descritas como numericamente distintas umas das outras. Ora, se o objeto não pode ser imanente, logo ele é transcendente, ou seja, a consciência visa, por meio de 
operações imanentes, algo transcendente.

Uma vez que a transcendência do objeto percebido é uma determinação descritiva e não ontológica, podemos compreender porque Husserl afirma que o objeto deve ser transcendente ao ato "independentemente de saber em que sentido e com que direito se fala de seu 'ser' " (HUSSERL 2012, 354; cf.1901, 384). Dada essa situação, é preciso observar que a afirmação de que o objeto intencional é transcendente à vivência:

1. Não implica, a princípio, que ele seja independente ou dependente ontologicamente da consciência.

2. Não implica, a princípio $^{8}$, que ele seja real ou exista, mas também não implica que ele seja irreal.

Por entender a fenomenologia como uma ciência metafisicamente neutra, Husserl se abstém de abordar frontalmente a relação entre o objeto intencional e um suposto mundo físico, ontologicamente independente da consciência. Limita-se a afirmar que o problema acerca da existência de átomos, moléculas e vibração do ar diz respeito à metafísica. "O problema da existência e da natureza do mundo externo é um problema metafísico”. (2012, 18; cf. 1901, 20)

A consciência "visa" (meinen) um objeto transcendente, sendo fenomenologicamente irrelevante se este objeto intencionado é, em si, uma ilusão ou não, se existe ou não. A diferença entre percepção e alucinação é fenomenologicamente irrelevante, na medida em que a descrição de ambas seja idêntica. Mas isso é revelador. Como a intencionalidade da consciência independe da existência ou inexistência do objeto, a relação intencional do sujeito ao objeto não é

\footnotetext{
${ }^{8}$ A princípio, não haveria motivos, mas Husserl acaba identificando, sexta investigação lógica, o objeto da percepção com o objeto real.
} 
uma relação real entre duas realidades. Não se trata de uma relação causal entre o objeto e a consciência, entre uma realidade interior e uma realidade exterior (ontologicamente independente). A vivência intencional não é produzida por um objeto exterior que, ao afetar a sensibilidade do organismo, acaba afetando a consciência. Pelo contrário, são os componentes internos à própria vivência que determinam sua referência a este ou aquele objeto (HUSSERL 2012, 353). A intencionalidade da consciência, sua direcionalidade a uma transcendência, é produzida por elementos imanentes à vivência.

Em suma, quando Husserl considera o objeto intencional como exterior, é preciso observar que essa é uma determinação descritiva, de onde não se pode inferir que o objeto intencional venha identificado com a coisa física. Desde então, a pergunta que se coloca, em especial na esfera da percepção, é sobre a relação entre três instâncias:

1) a aparição do objeto;

2) o objeto que aparece;

3) o objeto da física.

Sabemos que a aparição do objeto é imanente e que o objeto percebido é transcendente. Mas e o objeto da física? Tratar-se-ia de uma transcendência que, ao contrário do objeto percebido, não aparece? Haveria portanto implicitamente em LU dois e não um único conceito de transcendência? Como iremos mostrar ao longo deste artigo, tudo parece sugerir que devemos distinguir duas transcendências já na primeira edição de LU, a saber:

A) Uma transcendência em sentido metafísico, que, por princípio, não pode vir à doação intuitiva, como podemos observar na seguinte passagem:

Separada completamente da Teoria do Conhecimento está a questão 
acerca do direito com que admitimos realidades "psíquicas" e "físicas” („psychische" und „physische" Realitäten) diferentes do nosso próprio eu, o que é a essência dessa realidade (Realitäten) e a que leis está subordinada, se a ela pertencem os átomos e as moléculas do físico, e coisas semelhantes. A questão acerca da existência e da natureza do "mundo externo" é uma questão metafísica (2012, 18; cf. 1901, 20, os grifos são nossos).

B) Uma transcendência que aparece e que não se confunde com a vivência da aparição (HUSSERL 2012, 354; 1901, 384).

Para a consideração fenomenológica reell, a própria objetividade não é nada; para falar em termos gerais ela é transcendente ao ato. Independentemente de saber em que sentido e com que direito se fala de seu "ser", independentemente de saber se é real ou ideal, se é verdadeira, possível ou impossível, o ato está "dirigido para ela" (HUSSERL 2012, 354).

Uma vez que temos limitado o problema, iremos mostrar os seguintes pontos. Em primeiro lugar, que a transcendência que aparece é dependente da consciência, na medida em que é resultante de operações imanentes (DRUMMOND 2003, 66). Em segundo lugar, que Husserl pressupõe em LU a concepção de uma transcendência que não aparece, ao delimitar o campo da fenomenologia pela exclusão do corpo físico. Em terceiro lugar, que essa preconcepção é incompatível com o desenvolvimento consequente da fenomenologia tomada como teoria do conhecimento. Em quarto lugar, que a compreensão desta incompatibilidade é um passo fundamental para a virada transcendental e o estabelecimento do campo da fenomenologia a partir de um novo conceito de imanência, como imanência pura ou transcendental, que é, segundo Husserl, o verdadeiro absoluto. 


\section{A TRANSCENDÊNCIA QUE APARECE E A TEORIA DA APERCEPÇÃO HUSSERLIANA}

Ao examinar a teoria da percepção de Husserl, podemos obter valiosas informações referentes ao problema da dependência ou independência do objeto percebido com relação à consciência. Em LU, a percepção é compreendida como uma apreensão objetivante de sensações, através da qual se constitui a aparição do objeto. Em função de uma apreensão objetivante, as sensações são interpretadas como transcendentes, como a manifestação de um objeto ou de suas propriedades objetivas (HUSSERL 2012, 331). Por sensações, devemos entender algo de subjetivo, algo que pertence ao fluxo. Nas percepções normais, as sensações são vividas, mas não percebidas. É apenas por meio de uma apreensão deste algo pertencente ao fluxo que um objeto transcendente aparece.

Tomemos como exemplo o caso da percepção sensível de uma esfera amarela. O termo "amarelo" pode designar tanto uma sensação, entendida como momento pertencente à aparição, quanto uma propriedade transcendente (qualidade cromática amarela) do objeto aparecente (HUSSERL 2012, 109; 1901, 128). Quando afirmamos que o objeto percebido é amarelo, designamos uma propriedade do objeto, mas não a sensação do amarelo, a qual é momento da aparição. Ou seja, a qualidade amarela do objeto é resultante da interpretação objetivante da sensação amarela. $\mathrm{O}$ objeto transcendente, dado na percepção, possui a propriedade transcendente de ser amarelo graças à interpretação objetivante da sensação imanente do amarelo.

Para Husserl essa interpretação objetivante é sempre realizada mediante um sentido (Sinn). Ou seja, perceber é in- 
terpretar objetivamente as sensações com um determinado sentido. E as propriedades objetivas aparecentes que pertencem ao objeto são resultantes da interpretação objetivante das sensações. Desde então, algo fica fortemente sugerido: $a$ transcendência do objeto aparecente, bem como suas propriedades, são dependentes de operações imanentes. E mais, as propriedades objetivas do objeto são correlatas de sensações. A propriedade amarela do objeto é correlata da sensação de amarelo imanente. O limão é azedo como resultado da apreensão objetivante da sensação de azedo. Ou seja, a relação entre sensação e propriedades transcendentes não é arbitrária e o sentido (Sinn) pelo qual o conteúdo imanente é interpretado é limitado pelos próprios dados de sensações. Uma sensação de amarelo, uma vez apreendida, não pode propiciar a aparição de um objeto verde. A cada uma das sensações, auditivas, gustativas, sonoras, corresponde uma propriedade objetiva, resultante de sua apreensão objetivante.

Mas não só, Husserl atribui às sensações uma "forma inautêntica de espacialidade". Esta, uma vez apreendida, constitui o espaço autêntico. Assim, na III Investigação, \$9, Husserl escreve: "É evidente que nós compreendemos aqui por "espacialidade" o momento de sensação, cuja apercepção objetiva constitui a espacialidade aparecente e autêntica (erscheinende und eigentliche Räumlichkeit)" (HUSSERL 2012, 209; cf.1901, 241). Daí que devemos também dizer que o espaço objetivo transcendente é resultante de operações imanentes. Ou seja, pela apreensão do espaço imanente das sensações se constitui o espaço objetivo transcendente no qual se encontra os objetos percebidos. Tudo leva a crer mais uma vez que esse espaço constituído não é o espaço físico tal como concebido pelas teorias físicas. A física não es- 
tuda um espaço produzido por operações na consciência psíquica, mas sim um espaço que existe independente da existência da consciência pertencente a entes de uma determinada espécie animal.

\section{ELUCIDAÇÃO DAS CONTRADIÇÕES RESULTANTES DOS DOIS CONCEITOS DE TRANSCENDENNCIA}

Tendo em vista o que foi anteriormente exposto, devemos considerar que, apesar de todos os esforços de Husserl, algo permanece em aberto em LU. Qual o tipo de vínculo ontológico que existe entre o objeto aparecente e as aparições? $\mathrm{O}$ que significa a transcendência do objeto em relação à sua aparição? Como iremos observar em mais detalhes, esses problemas se agravam ao se observar que a esfera fenomenológica, a qual pertence à aparição, é obtida por uma abstração do eu empírico, ou seja, pela exclusão do corpo físico (2012, 301; cf.1901, 331). Isso nos leva a considerar que a transcendência do objeto intencional contém obscuridades, posto que, de um lado, o objeto que aparece como transcendente é resultado de operações puramente imanentes; por outro lado, essas operações se passam em um domínio de imanência que foi obtido justamente pela abstração do lado físico de um homem real que faz parte da natureza. Seria a transcendência do corpo físico e dos demais objetos físicos a mesma do objeto que aparece? Para que tal identificação fizesse algum sentido, teríamos que supor que a transcendência constituída na imanência psíquica (sensação + apreensão objetivante) milagrosamente coincidisse com a realidade exterior física que, de saída, foi excluída para a obtenção do campo fenomenológico. Como uma transcendência produzida pela imanência pode coin- 
cidir com uma suposta realidade exterior que, por definição, é independente da consciência?

Tendo em conta o que foi discutido acima, fica claro que o objeto perceptivo que aparece como transcendente não pode ser confundido com o objeto da física, já que este não possui qualidades sensíveis, mas apenas qualidades lógico-geométricas. A situação torna-se ainda mais complexa com uma decisão ontológica realizada por Husserl na sexta investigação, onde ele identifica o objeto sensível e o objeto real (2007, 146/157; cf. 1901, 616/628). Com isso, ele adota uma forma de "realismo perceptivo": ser real significa ser dado intuitivamente "em pessoa" em atos de percepção sensível. Como consequência, uma qualidade cromática torna-se não só propriedade de um objeto transcendente, mas uma propriedade real de um objeto real. Contudo, um átomo não é vermelho ou amarelo. Quente e frio não se confundem com a energia cinética das moléculas de um objeto físico. Se assim é, devemos então mais uma vez retomar a pergunta: qual a relação entre esse objeto transcendente dado na percepção e o objeto da física? Seria o objeto da física, que não aparece e por princípio não pode aparecer, uma entidade irreal? Qual a relação entre o objeto sensível intuído e o objeto físico? De semelhança? De imagem? De signo? Temos acesso imediato ao objeto transcendente da percepção e apenas acesso mediato ao mundo físico? Ou seria essa uma pergunta que a fenomenologia, tomada como psicologia descritiva, por princípio não pode responder? Mas se Husserl é incapaz de oferecer uma resposta satisfatória, esse não seria um lamentável limite de uma epistemologia realizada no marco de uma psicologia descritiva?

É importante frisar que, em 1901, Husserl assume uma posição neutra com relação à metafísica. Essa neutralidade, 
entretanto, não significa que ele rejeite a metafísica e a existência de uma realidade exterior independente. Husserl deixa a entender que a física, por exemplo, se consuma sobre um pressuposto metafísico (2012, 18; cf. 1901, 20). A mera rejeição do pressuposto sobre o qual física se efetiva não implicaria nenhum tipo de ganho, a menos que a fenomenologia fosse capaz de oferecer uma proposta alternativa, restabelecendo-a sobre novas bases. A física pretende estudar a realidade física e esta não pode ser identificada ipsis litteris com a realidade que aparece tal como aparece. Com isso, aquele velho problema da relação entre o sujeito e a realidade exterior, problema esse posto por Descartes e que a doutrina das qualidades primárias e secundárias de Locke busca responder, não é eliminado pela fenomenologia de LU. Pelo contrário, a dificuldade quanto ao acesso da realidade exterior ressurge sob uma forma mais refinada. $\mathrm{O}$ antigo problema da relação entre experiência sensível e realidade exterior torna-se agora o problema da relação entre uma transcendência que aparece, em função de momentos imanentes à consciência e que, portanto, não é plenamente independente do sujeito, e uma transcendência física, que não aparece de maneira direta.

Como pretendemos mostrar neste artigo, por maior que seja a neutralidade metafísica de Husserl, esta transcendência física encontra-se pressuposta, já que é pela desconsideração ou exclusão desta última que a fenomenologia, tomada como psicologia descritiva, circunscreve seu domínio. E essa pressuposição, presente em 1901, resulta basicamente do fato de Husserl estar preso à atitude natural, na qual permanece implícito um realismo ingênuo. A teoria do conhecimento que se originava a partir do pressuposto de um mundo exterior era incapaz do legitimar qualquer for- 
ma de conhecimento a respeito deste último. Em suma, a epistemologia fundamentada em uma psicologia descritiva cujo domínio era alcançado pela exclusão do mundo físico acabava carregando pressupostos ontológicos conflitantes com suas premissas epistemológicas. Esses pressupostos permaneciam em 1901 implícitos na concepção da fenomenologia como uma teoria do conhecimento fundamentada na consciência de indivíduos psicofísicos. Assim, a fenomenologia carregava consigo, já em seu ponto de partida, uma concepção não fenomenológica de transcendência, diferente de uma concepção descritivo-fenomenológica de transcendência.

\section{A VIRADA TRANSCENDENTAL E A REARTICULAÇÃO DOS CONCEITOS DE IMANÊNCIA E TRANSCENDÊNCIA}

Husserl, na primeira edição de Investigações Lógicas, havia concebido sua fenomenologia como uma epistemologia fundada na psicologia descritiva. Ao restringir suas análises às vivências cognitivas pertencentes à imanência psíquica, ele acreditava que a fenomenologia poderia ser metafisicamente neutra. Sua ideia era que seria possível erigir uma teoria do conhecimento a partir de uma reformulação de seu problema de base. Ao invés de abordar o problema do conhecimento como uma relação entre a realidade psíquica e a realidade exterior, ele se propunha a recolocar o problema a partir da imanência, ou seja, como concernente à relação entre diferentes formas de vivências intencionais, nomeadamente, intuitivas e signitivas. Se o problema do conhecimento pudesse receber um tratamento adequado a partir da pura imanência, aparentemente não haveria razão para sair da esfera da psicologia descritiva e adentrar em 
problemas metafísicos concernentes à realidade exterior. É isso que Husserl pensa em 1900/1901.

Mas poucos anos depois ele percebe que a sua teoria do conhecimento extrapolava o âmbito da psicologia e tinha sim claras implicações ontológicas, que haviam the passado despercebidas. (1962, 43/253). Em 1906/7, quando descobre o método da redução transcendental, ele passa a rejeitar a determinação da fenomenologia como metafisicamente neutra, afirmando, pelo contrário, que uma epistemologia consequente só era possível como filosofia transcendental e esta, pelo seu turno, possibilitaria a fundamentação de uma metafísica dotada de autênticos direitos (HUSSERL 2008, 2).

A fenomenologia, concebida como filosofia transcendental é, para Husserl, o desenvolvimento consequente da nova teoria do conhecimento apresentada em LU. (HUSSERL 1962, 43). Em 1911 em seu artigo "Filosofia como ciência de rigor", Husserl (1965) afirma que, embora em LU ele tenha detectado o psicologismo lógico, decorrente da naturalização das idealidades, ele não havia se dado conta de outra forma de psicologismo, decorrente de uma concepção naturalizada da consciência, concepção essa que está na base da própria definição da psicologia. A fim de libertar a fenomenologia de LU de sua carga psicológica, Husserl opera algumas modificações no texto da segunda edição. Destas, merece destaque a distinção de três tipos de conteúdos, que na primeira edição eram identificados: conteúdo psicológico-descritivo (real), conteúdo fenomenológico, conteúdo reell. Desde então, como bem mostra Boehm (1968), Husserl irá distinguir, a partir de 1907, três conceitos de imanência:

1) Imanência real. Trata-se da esfera de vivências obti- 
das pela abstração do corpo físico. Na primeira edição Husserl denomina de "eu empírico" o conjunto composto por corpo físico e uma esfera de vivências. O domínio da fenomenologia é obtido justamente pela exclusão do corpo físico, como se observa na seguinte passagem:

Se separarmos o eu corporal do eu empírico e se limitarmos, portanto, o eu psíquico puro ao seu teor fenomenológico, então ele reduzse à unidade de consciência, por conseguinte, à complexão real (reell) de vivências que nós (ou seja, cada um para seu próprio eu), numa parte, encontramos com evidência como disponível para nós próprios e que, na parte restante, com fundadas razões supomos (HUSSERL 2012, 301).

Podemos dizer que este conceito de imanência real é análogo ao conceito cartesiano, pois permanece implícita a suposição de que se trata do cogito de um homem, que possui um lado físico, que permanece pressuposto, e um lado psíquico, tido como absolutamente dado. Uma vez que em LU o domínio da fenomenologia é obtido pela abstração do corpo, é claro que o corpo, tomado como base material das vivências (e não como mero correlato objetivo das vivências), permanece como dado de antemão, pois do contrário não haveria sentido apartá-lo do domínio da fenomenologia ${ }^{9}$. Mas a noção de operar uma abstração do corpo para se alcançar o domínio da fenomenologia é algo que só faz sentido sobre o solo da atitude natural, de onde resulta uma concepção de transcendência ingênua, como "mundo exterior". A fenomenologia de LU, na medida em que encontra seu domínio pela abstração do corpo, abstém-se de tratar os problemas concernentes à natureza da exterioridade suposta

\footnotetext{
${ }^{9}$ É importante ressaltar aqui que, na primeira edição de LU, Husserl não distingue entre corpo vivo (Leib) e corpo fisiológico (Korper), como mais tarde irá fazer. O corpo próprio é tomado como mais um objeto na natureza, sem nenhum status privilegiado, como terá posteriormente.
} 
e que foi abstraída, cuja investigação é relegada à metafísica.

2) "Imanência reell". Designa o fluxo constituído pelas vivências purificadas de sua apercepção psicológica, como podemos observar em A Ideia da fenomenologia "O imanente reell surge como o indubitável, pois nada mais exibe para além de si mesmo". (HUSSERL 2008, 22; cf.1973, 5). Ao efetuar a reflexão, não tenho evidência apodítica de que as vivências que me são dadas são vivências de um ser humano, que é parte do mundo. De certo modo, podemos afirmar que a imanência reell é a imanência real sem contaminações transcendentes. $\mathrm{O}$ conceito de transcendência obtido por contraposição a esse conceito de imanência reell é distinto do conceito anterior. Todo conteúdo impróprio de um ato (os conteúdos ideais e os objetos intencionais dados em atos não reflexivos) é, nesse sentido, transcendente. E não só, pois também o próprio sujeito psíquico, tomado como parte de um sujeito real é algo transcendente, bem como suas vivências, uma vez que sejam tomadas como estados deste ser psicofísico.

3) "Imanência pura", no sentido de datidade absoluta. A imanência reell, constituida pelos conteúdos reells é apenas um caso especial da imanência pura (BOEHM 1968). Esta última é constituída pelos conteúdos fenomenológicos, ou seja, por tudo aquilo que "é dado evidente no sentido genuíno, dado absoluto do ver puro" (HUSSERL 2008, 27). Para alcançar o dado absoluto é preciso realizar a epoché, ou seja, da suspensão da tese de existência do mundo. Husserl afirma que essa imanência pura pode ser circunscrita em três níveis de consideração fenomenológica. No primeiro nível, entra a imanência reell, trata-se do cogito tomado em sua singularidade (HUSSERL 2008, 26). No segundo grau entram os universais (eidos), o que possibilita a fenomeno- 
logia como ciência eidética noética. No terceiro, os correlatos (cogitata) de toda espécie, na medida em que são constituídos na consciência, o que possibilita a fenomenologia como ciência universal da correlação noético-noemática. No caso da percepção exterior, tais correlatos pertencem à imanência pura, mas não à imanência reell.

Uma vez que estamos em posse destes três conceitos de imanência e transcendência, podemos agora concluir o seguinte. Se em 1901, Husserl faz a distinção entre a aparição e o que aparece, em 1907 ele acrescenta que essa distinção deve ser realizada no interior da imanência pura. Tanto a aparição quanto aquilo que aparece são imanentes no sentido absoluto. Contudo, a aparição do objeto pertence à imanência reell enquanto o objeto aparecente é transcendente com relação à imanência reell. "Por conseguinte, temos dois dados absolutos, o dado do fenômeno e o dado do objeto; e o objeto, dentro desta imanência, não é imanente no sentido incluso (reell)." (2008, 29). Objetos da percepção, entendidos de maneira reduzida, também podem ser dados em sentido absoluto, tanto quanto a sua aparição (fenômeno), ainda que a doação de objetos espaçotemporais necessariamente seja por perfis.

Cada conceito de imanência tem como contraponto um conceito de transcendência. Em primeiro lugar, temos o conceito de imanência psicológico-descritivo, que compreende a consciência como uma região ontológica do mundo, ao lado de outras regiões que lhe são transcendentes. A imanência psíquica é tomada apenas como um objeto dentre outros tantos objetos possíveis de investigação científica. Em segundo lugar, o conceito de imanência reell tem um conceito relativo de transcendência: todo conteúdo fenomenológico que não é reell é transcendente, como por 
exemplo, as essências e os correlatos objetivos das vivências intencionais. Neste sentido, o objeto percebido tal como percebido é transcendente. Se os dois primeiros conceitos de imanência possuem conceitos bem definidos de transcendência, isso não se pode dizer do terceiro conceito. $\mathrm{O}$ problema se coloca quando buscamos um conceito de transcendência contraposto à imanência transcendental, que é o que iremos observar a seguir.

\section{O PROBLEMA DA TRANSCENDÊNCIA PURA}

O domínio da fenomenologia, após 1907, não é mais obtido pela exclusão daquilo que é transcendente ao conteúdo reell, mas pela "desconexão" de tudo aquilo que é transcendente à imanência pura, ou seja, tudo aquilo que não é dado após a efetuação da redução transcendental. Mas o que não é dado após a efetuação da epoché? A única resposta é: o que não é e não pode ser dado, ou seja, aquilo que não pode, a princípio, ser constituído pela consciência. Com isso desloca-se a pergunta: o que é que não pode ser constituído pela consciência? A resposta mais óbvia pareceria ser: o mundo real, o mundo em si, ontologicamente independente da consciência. Ainda que essa seja a resposta mais óbvia, ela é problemática. Como Husserl faz notar em 1913, a redução não implica em nenhuma perda, pois aquilo que foi desconectado, caso se trate de algo dotado de algum tipo de validade, deve ser agora reconectado, "reconduzido" à esfera de datidade absoluta e aceito na justa medida em que é dado. Isso levará Husserl a afirmar que, do ponto de vista transcendental, a própria concepção de um mundo ontológico independente da consciência é um contrassenso. Todo objeto possível de ser conhecido, predi- 
cado e experienciado é correlato de operações noéticas. Quando a consciência é vista a partir de uma perspectiva em terceira pessoa, como uma coisa entre outras coisas, não é possível desvelar sua dimensão transcendental. E querer compreender a constituição do mundo pela consciência desde a perspectiva da atitude natural é recair em psicologismo e contrassenso.

Contudo, quando a consciência não é vista sob uma perspectiva naturalística em terceira pessoa, mas a partir da redução transcendental, não há exterioridade, nem interioridade. Interioridade ou exterioridade são dois momentos correlatos que entram na imanência pura. (SOKOLOWSKI 1974). O sujeito transcendental é condição do aparecimento de qualquer ente possível. Um dos maiores ganhos da redução é que ela revela o vínculo essencial que há entre ser e aparecer. E a essência de um objeto transcendente não é algo que se esconde por trás de seu aparecer, mas diz respeito ao próprio modo como objeto necessariamente deve aparecer. A postulação de um ser que, em princípio, não se manifesta e não se anuncia nem mesmo ao pensamento teórico, é algo que faz sentido? A objeção de que a redução limita o campo de pesquisa à interioridade, ainda que transcendental, só pode ser resultante de uma má compreensão da mesma, uma má compreensão derivada da confusão da atitude transcendental com a atitude natural. Como aponta Zahavi $(2003,45)$, se há algo que a epoché exclui, esse algo não é a própria realidade, mas apenas uma concepção absurda da mesma, nomeadamente, uma realidade independente de toda teoria, de toda experiência. 


\section{CONCLUSÃO}

A partir de 1906, com a virada transcendental, Husserl entende que a epistemologia não deve se fundamentar na psicologia descritiva, mas sim na filosofia transcendental. Desde então, o domínio autêntico da fenomenologia, entendida como filosofia transcendental, não é mais a imanência psíquica, mas sim a imanência pura. Nesta, entram não só as vivências purificadas, mas também as essências e todos os correlatos constituídos pela consciência. $\mathrm{O}$ objeto aparecente passa a ser entendido sobre uma dupla chave: como transcendente aos conteúdos reells, mas imanente em sentido puro. Essa ampliação do campo da fenomenologia possibilita Husserl solucionar vários problemas presentes em LU, inclusive a respeito do status do objeto intencional. Com isso, em Ideias, Husserl busca oferecer uma solução a duas relações que permaneciam em aberto em LU.

1. A relação entre aparição e o objeto que aparece. Em LU, Husserl parecia sugerir uma separação real entre ambos (MOURA 1989). Em Ideias I, com a defesa do primado da consciência em relação ao ser transcendente, Husserl pode oferecer uma solução ao vincular de maneira bem mais estreita a aparição do objeto com o objeto que aparece. $\mathrm{O}$ objeto que aparece e a aparição valem como momentos de um mesmo todo. O objeto percebido nada mais é do que "o idêntico de multiplicidades de aparições motivadas de modo coerente”. (HUSSERL 2006, 116). Ele não é nem a soma das aparições, nem algo por trás destas, e muito menos algo destas realmente separado, mas apenas aquilo que as unifica como aparições de uma mesma unidade.

2. A relação entre objeto da física e o objeto da percepção. Em Ideias I, Husserl rejeita a doutrina das qualidades 
secundárias. Não há razão para considerar que as qualidades primárias possuem algum privilégio frente às secundárias, já que estas dependem daquelas. Sem cor, a superfície espacial não pode se manifestar. Husserl rejeita também a doutrina de que o objeto dado na intuição é signo de um segundo objeto, ou seja, o objeto físico. Mas então, qual a relação entre ambos os objetos? No \$52 de Ideias I, ele irá oferecer uma solução para este problema a partir da concepção de que o objeto da física é constituído a partir de operações noéticas realizadas sobre o objeto da percepção. Ou seja, o portador das determinações sensíveis será concebido como idêntico ao portador das determinações físicas (HUSSERL 2006, 121), de modo que, do ponto de vista transcendental, não se poderá afirmar que a coisa física é algo que existe por trás do objeto sensível e que é sua "causa” (HUSSERL 2006, 120; cf. BOER 1978, 416-420). Se o objeto físico fosse uma causa escondida por trás do objeto que aparece, teríamos, como consequência, uma teoria dos dois mundos, na qual haveria uma realidade fenomênica e, por trás desta, uma realidade física. É verdade que o objeto da física possui atributos que não são dados no objeto tal qual ele se manifesta na experiência direta, ao passo que este possui atributos que estão ausentes naquele. Mas isso não é problema, já que é preciso distinguir entre o portador das determinações e as próprias determinações. $\mathrm{O}$ portador das determinações é o mesmo, já as determinações de um e de outro variam de acordo com o tipo de ato e do sentido com o qual é intencionado. E isso não significa que não haja uma relação entre as determinações físicas e as determinações percepcionadas. $\mathrm{O}$ objeto, enquanto portador das determinações sensíveis, tal como dado na intuição doadora originária, possui não só primazia epistemológica, mas 
também ontológica frente ao objeto da física. Este é constituído por um processo de idealização operado sobre a objetividade dada na intuição. As próprias determinações físicas se anunciam, antes de qualquer teoria, nas determinações sensíveis (1912/1952, 75-77). Em suma, todo conhecimento científico teórico encontra sua raiz na intuição doadora originária. Essa ideia irá culminar, na posição amplamente desenvolvida por Husserl nos anos de 1920, de que os diferentes domínios das ciências teóricas encontram sua raiz no mundo circundante (Umwelt) (HUSSERL 1925/1962, 5564) e, posteriormente, naquilo que ele irá denominar de mundo da vida (Lebenswelt) (HUSSERL 1976).

Abstract: It is well known that in the first edition of Logical Investigations (1900/1901), Husserl defines the research field of phenomenology as a psychological immanence. However, if we closely examine the criteria used for defining the psychological immanence, we find that they imply certain conception of transcendence of the intentional object. This conception of transcendence leads to epistemological problems concerning the relationship between the physical object and the object of perception. After all, it would be correct to say that the physical object is transcendent in the same sense which it is stated that the perceived object is transcendent to the experience of perceiving? This article seeks to show how the transcendental turn of 1906/1907 and the consequent distinction between three concepts of immanence and transcendence in his work Idea of Phenomenology contributed to solving such problems.

Keywords: Edmund Husserl; phenomenology; immanence; transcendence.

\section{REFERÊNCIAS}

BOEHM, R. Vom Gesichtspunkt der Phänomenologie. Den Haag: Nijhoff, 1968.

BOER, T. D. The development of Husserl's thought. The Hague; Boston: Nijhoff, 1978.

DRUMMOND, J. J. The Structure of Intentionality. In: 
WELTON, D. (Ed.). The new Husserl a critical reader. Bloomington, IN: Indiana University Press, 2003. p.65-92.

HUSSERL, E. Logische Untersuchungen 1: Prolegomena zur reinen Logik. Halle a/S.: Niemeyer, 1900. Disponível em: $<\quad$ http://www.freidok.unifrei-

burg.de/volltexte/5920/pdf/Husserl_Logische_Untersuchu ngen_1_1900.pdf $>$.

- Logische Untersuchungen 2: Untersuchungen zur Phänomenologie und Theorie der Erkenntnis. Halle: Niemeyer, 1901. Disponível em: < https://archive.org/details/logischeuntersu01hussgoog $>$. Acesso em: 24/03/2014.

. Ideen zu einer reinen Phänomenologie und phänomenologischen Philosophie; Buch 2, Phänomenologische Untersuchungen zur Konstitution. Den Haag: Nijhoff, 1952.

. Phänomenologische Psychologie: Vorlesungen Sommersemester 1925. Husserliana IX. Haag: Martinus Nijhoff, 1962. 1965.

A filosofia como ciência de rigor. Coimbra: Atlântica,

. Die Idee der Phänomenologie: fünf Vorlesungen. Hamburg: F. Meiner, 1973.

- Die Krisis der europäischen Wissenschaften und die transzendentale Phänomenologie: eine Einleitung in die phänomenologische Philosophie (Husserliana IV). Haag: M. Nijhoff, 1976. 
- Idéias para uma fenomenologia pura e para uma filosofia fenomenológica: Introdução geral à fenomenologia pura. Aparecida: Idéias \& Letras, 2006.

. Investigações lógicas. Segundo Volume. Parte II, Investigações para a fenomenologia e a teoria do conhecimento. Lisboa: Centro de filosofia da Universidade de Lisboa, 2007.

. A idéia da fenomenologia. Lisboa: Edições 70, 2008.

. Investigações lógicas. Segundo Volume. Parte I, Investigações para a fenomenologia e a teoria do conhecimento. Lisboa: Forense, 2012.

MOURA, C. A. R. Crítica da razão na fenomenologia. EDUSP, 1989.

SOKOLOWSKI, R. Husserlian Meditations: How Words Present Things. Northwestern University Press, 1974.

ZAHAVI, D. The Three Concepts of Consciousness in the 'Logische Untersuchungen'. Husserl Studies, v. 18, n. 1, p. 51-64, 2002.

ZAHAVI, D. Husserl's phenomenology. Stanford, Calif.: Stanford University Press, 2003. 